\title{
Severity and Magnitude of Caries among Rural Populations in Ferlo in Senegal
}

\author{
Diouf Massamba1* ${ }^{*}$, Boetsch Gilles², Cisse Daouda1, Lo Cheikh Mouhamadou Mbacké1, \\ Kanouté Aida1, Diop Mbatio1, Barro Ibrahima1, Faye Daouda1 \\ ${ }^{1}$ Public Health Service, Department of Dentistry, Cheikh Anta Diop University, Dakar, Senegal \\ ${ }^{2}$ CNRS-UMI “Environment, Health, Society", Marseille, France \\ Email: *dioufmass78@yahoo.fr, *mass78@voila.fr
}

Received 5 January 2016; accepted 19 January 2016; published 22 January 2016

Copyright (C) 2016 by authors and Scientific Research Publishing Inc.

This work is licensed under the Creative Commons Attribution International License (CC BY). http://creativecommons.org/licenses/by/4.0/

(c) (i) 0pen Access

\begin{abstract}
Oral diseases belong to non-communicable diseases. They are characterized by their importance especially in disadvantaged areas. The objective of this study was to measure the extent and severity of caries among rural populations of Widou, an area located in central Ferlo. It was a descriptive and cross-sectional study which involved 300 individuals selected using simple random sampling. The socio-demographic characteristics collected were sex, age, educational level and occupation. The dental status was rated by the prevalence of dental caries and DMF and its components. The data were analyzed with the software Epi info 3.4.5 with $5 \%$ of threshold statistical significance. The prevalence of dental caries was $89 \%$. The mean DMF was $5.4 \pm 5.6$ with a maximum of 26. The mean of component " $D$ " was 3.8 with a maximum of 24 . Variables significantly associated with dental caries were sex $(p=0.012)$ and occupation $(p=0.03)$. The extent and severity of caries in rural areas of the Ferlo evoke a relatively low support or management and require efforts in prevention, directed on oral hygiene and dietary habits.
\end{abstract}

\section{Keywords}

Dental Status, Rural Population, Ferlo, Senegal

\section{Introduction}

The oral diseases belong to non-communicable diseases. They now constitute a public health problem [1]. The oral cavity is a crossroad of several essential functions. For this purpose, it is important that care is available and beneficial to all people. But in some areas, particularly disadvantaged, by geographic, financial and cultural

\footnotetext{
${ }^{*}$ Corresponding author.
}

How to cite this paper: Massamba, D., Gilles, B., Daouda, C., Mbacké, L.C.M., Aida, K., Mbatio, D., Ibrahima, B. and Daouda, F. (2016) Severity and Magnitude of Caries among Rural Populations in Ferlo in Senegal. Open Journal of Epidemiology, 6, 10-15. http://dx.doi.org/10.4236/ojepi.2016.61002 
problems of accessibility, dental cares continue to be a major concern for people and the government. The World Health Organization (WHO) indicates that $90 \%$ of the populations have at least one cavity. The WHO report on health in the world, showed that a number from 5 to 6 decayed teeth per person in some developing countries [2]. Dental Caries is an irreversible microbial disease of the calcified tissues of the teeth, characterized by demineralisation of inorganic portion and destruction of organic substance of the tooth, which often leads to cavitation. It is often left untreated and can impact negatively on general health, and physical, developmental, social and learning outcomes. The greatest burden of dental caries is seen in those of low socio-economic position. Other risk factors include high and frequent consumption of refined carbohydrates (predominately sugars), and soft drinks and other sweetened beverages, and low intake of (fluoridated) water [3]-[5]. The high prevalence of oral diseases is after rapid urbanization of cities, lack of hygiene and the persistence of harmful traditions and beliefs to health. In Africa, for example, in Madagascar since 1996, studies have revealed that most Malagasy are carriers of caries of interest from 10 to 12 per person [2]. In Senegal, several isolated studies have found high prevalence of oral diseases [6] [7]. These indicators are larger in rural areas. The aim of our study was to assess the severity and magnitude of dental caries of Widou populations in Ferlo.

\section{Methodology}

\subsection{Type Setting and Studied Population}

The study was descriptive and cross-sectional and included people living in the centre of Ferlo. The survey took place in Widou-Thiengoli village, at the Middle East Centre of Senegal. The choice of this area was guided by its geographical position in the "Great Green Wall”, an international project to limit desertification, its polarised population, the existence of functional health centre, and the vital role it plays in the economy of the Ferlo.

\subsection{Selection Criteria}

To be included in the study, individuals should have been born in the area or have lived there for at least ten years, presumed to be sufficient time for negative behaviours and attitudes to have an effect on the health of teeth, should have adequate general health to allow oral clinical examination and be available and willing to participate in the study.

\subsection{Sampling and Sample Size}

The required sample size was based on a calculation according to the Schwartz formula:

$$
n=(\varepsilon \alpha)^{2} p q / i^{2}
$$

[8] that can be used in cross-sectional studies where $\varepsilon=1.96=$ standardised normal deviate; $\alpha=$ level of significance $=0.05 ; p=0.89$ = prevalence of the health feature (dental caries) found from a pilot survey [9]; $q=1-p$ $=0.11 ; i=5 \%=$ accuracy. These data suggested a sample size of 150 persons. Given that the power of the study increases with the size of the study, this number was multiplied by 2, giving a size of 300 persons. Participant recruitment was by simple random sampling. After establishing lists of potential participants, 300 people were drawn from the list by chance. When an individual did not meet the selection criteria, he or she was not considered for the investigation and the next person on the list was selected.

\subsection{Data Collection, Studied Variables and Indicators}

The chosen data collection period was a 20 days civic holiday in which teams of doctors, pharmacists and dentists were deployed in the area to provide care, medication and counselling to people. Before administering the questionnaire, the objectives and importance of the survey were explained to the people, for their informed consent. The questionnaire had been pre-tested on 20 people living in a remote village (Tessekere) more than 20 kilometres distant. Data were collected using the WHO modified questionnaire about caries [10]. Four final year dental students, who had been previously calibrated and standardised in using the measurement technique acted as investigators. This was done to limit information bias. Data collection took place every day (from August 20 to 30, 2013) and concerned all persons living in the community and who met the selection criteria. Socio-demographic variables were based on gender, age group, educational level and occupation. Indicators related to dental state 
were based on prevalence, DMFt and its components. The prevalence of dental caries is the ratio between the total number of students with at least one cavity and the total number of examined students. It reflects the extent to which tooth decay exists. Any tooth that had a cavity related to caries, or a temporary filling or a recurrence of decay in a permanent filling was considered decayed. The DMFt index characterising the severity of the carious lesion shows the number of permanent decayed (D), missing (M) and filled (F) teeth among the studied population. Component $\mathrm{D}$ corresponds to all decayed teeth, component $\mathrm{M}$ corresponds to all missing teeth and component F corresponds to all teeth with permanent filling of cavities without recurrence.

\subsection{Ethical Considerations}

Before examination, each individual, provided free and informed consent. After performing the clinical examination, each person enjoyed a motivational and oral hygiene instruction session and received a pack containing a toothbrush and toothpaste. The information from each individual was treated confidentially.

\subsection{Data Analysis}

The software Epi Info 3.4.3 was the tool used to make data entry and data processing. The modalities of some variables as "age group" and "occupation" were grouped in statistical calculations for an epidemiological interest. The results of univariate analysis were expressed in frequency and mean with standard deviation. The comparison in bivariate analysis was made by the $\mathrm{Chi}^{2}$ test for the proportions. The tests were significant when the $p$ value was less than 0.05 .

\section{Results}

\subsection{DMFt and Its Components or Severity of Caries}

The mean DMFt was $5.4 \pm 5.6$ with a maximum of 26 .

The component "D" mean was 3.8 with a maximum of 24.

\subsection{Prevalence or Magnitude of Caries}

Dental caries prevalence was $89 \%$.

\section{Discussion}

This descriptive and cross-sectional study measured the DMFt and determined the caries prevalence of Widou populations in the Ferlo. This assessment reflects the severity and extent of tooth decay in this rural area inhabited mainly by Fulani who are most often cattleman.

\subsection{Methodological Limitations}

Although the sampling was random, it was based on individuals seeking health care from staff and students during the civic holiday. It is possible that persons who did not feel the need for care did not participate. Hence, there was a possibility of selection bias that would tend to higher the results because people who have not participated in the study may have fewer real needs that people who participated. Measurement bias due to different interpretations of DMFt index or caries prevalence should have been minimised, because the four dental students who collected the data had received training and calibration and were already accustomed to such measures.

\subsection{Severity of Dental Caries}

The mean DMFt was $5.4 \pm 5.6$ (Table 1). This value is 8 times higher than that found in a study of the rural population in Nigeria which was $0.67 \pm 2.0$ [11]. However, it is comparable with DMFt found in a rural adult population in India which was $5.1 \pm 3.9$ [12] and the DMFt found by Diouf et al. 2012 [9] about a cross-sectional study in the same area. The component "filled (F)" had the lowest average (0.01) with a maximum of 3 teeth filled (Table 1) on the entire sample. These results indicate a shortage or failure of the management of oral diseases in this locality. This weak support was noted in a study in India [12]. 


\subsection{Magnitude of Tooth Decay}

The prevalence of caries found in this study was $89 \%$ (Figure 1). Referring to WHO, prevalence higher than $80 \%$ is moderate to high [10]. It appears from this study that people living in the Ferlo had a high prevalence despite a virtually absent or low level of urbanization. This situation can be explained because population begin to change diet. Indeed, thanks to the nearby shops or frequency of weekly markets, they have access to new food products much more cariogenic [9]. Moreover, these people mostly farmers may have approximately a socioeconomic level relatively good, which further facilitates access to these products. These dietary changes from traditional type to "Western type" most often observed in urban and sub-urban areas are found increasingly in rural areas. Preventive health measures, which should imperatively accompany these changes are not likely implemented. With the purchasing power probably improved livestock cattleman or farmers, businesses will perhaps make their appearance in rural areas, and with them also the products with high cariogenicity. Tooth decay was significantly associated with sex and occupation (Table 2).

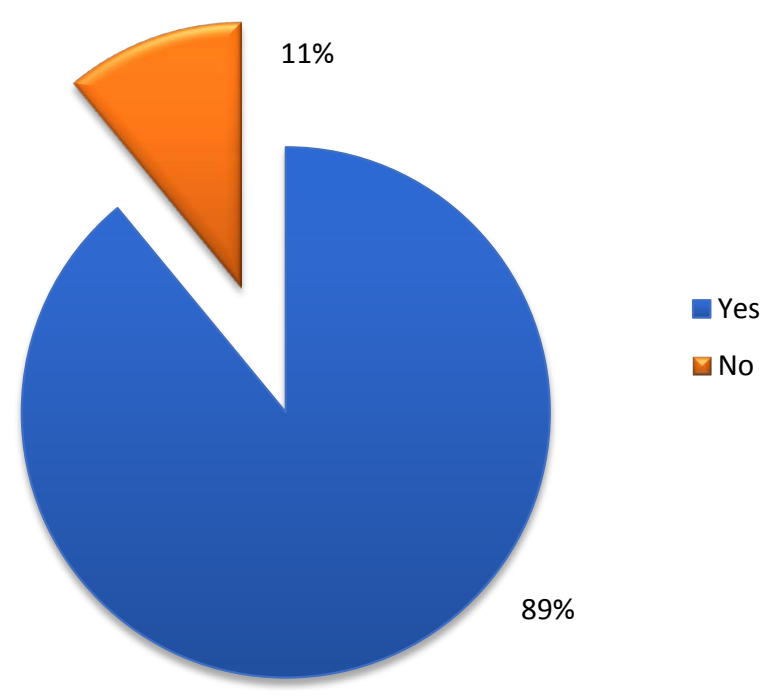

Figure 1. Prevalence of caries.

Table 1. Mean, standard deviation and maximum of the DMF index and its components.

\begin{tabular}{cccc}
\hline DMFt index and its components & Mean & Standard deviation & Maximum \\
\hline DMFt & 5.4 & 5.6 & 26 \\
Decayed teeth & 3.8 & 3.9 & 24 \\
Missing teeth & 1.6 & 3.4 & 23 \\
Filled teeth & 0.01 & 0.2 & 3 \\
\hline
\end{tabular}

Table 2. Association between caries prevalence and socio-demographic variables.

\begin{tabular}{|c|c|c|c|c|c|}
\hline \multirow{2}{*}{ Variables } & \multirow{2}{*}{ Modalities } & \multicolumn{2}{|c|}{ Carie (\%) } & \multirow{2}{*}{$\mathrm{Khi}^{2}$} & \multirow{2}{*}{$p$ value } \\
\hline & & Yes & No & & \\
\hline \multirow{2}{*}{ Gender } & Male & 82.9 & 17.1 & \multirow{2}{*}{6.3} & \multirow{2}{*}{0.012} \\
\hline & Female & 92.3 & 7.7 & & \\
\hline \multirow{2}{*}{ Age group } & Young & 92.0 & 8.0 & \multirow{2}{*}{2.21} & \multirow{2}{*}{0.13} \\
\hline & Adult & 86.6 & 13.4 & & \\
\hline \multirow{2}{*}{ Educational level } & Yes & 90.3 & 9.7 & \multirow{2}{*}{0.038} & \multirow{2}{*}{0.55} \\
\hline & No & 88.9 & 11.1 & & \\
\hline \multirow{2}{*}{ Occupation } & Yes (cattleman or farmer) & 85.5 & 14.5 & \multirow{2}{*}{4.6} & \multirow{2}{*}{0.03} \\
\hline & Non (housewife or unemployed) & 93.3 & 6.7 & & \\
\hline
\end{tabular}

The significantly associated socio-demographic variables with dental caries were gender $(p=0.012)$ and occupation $(0.03)$. 
These results are supported by some literature data [13]-[15] which have since demonstrated a statistically significant difference between decay and gender, with females being the most affected by caries. Indeed, African women, in general, are subject to time constraints. They play the leading role in the domestic economy, assuming, by far, the majority of the housework. Women suffer first the effects of the precariousness of local infrastructure as they bear the burden of collecting water and fuel. Many African women face a double work day, and have little time to devote to more productive activities and take care of their own health [16]. Varenne' results et al. [15] also reported a statistically significant relationship between the profession or occupation and caries. Being female was positively associated with more caries in terms of prevalence. The results obtained from the association between sex and caries on the one hand and between occupation and caries are comparable (Table 2).

\section{Conclusion}

The extent and severity of dental caries remain relatively high in rural populations of Ferlo. The transformation of rural area to an urban trend and the subsequent socio-environmental changes require different approaches to oral health. It is unlikely that improved oral health is effectively isolated by targeted interventions on specific behaviors. The most effective and sustainable interventions should combine social policy (based on equal opportunities and the fight against social inequalities) and individual action by promoting conditions through motivating changes in some of habits, substituting of starchy foods for sugary ones (or even simply judicious consumption of sugar). Although fluoridation of drinking water is a measure of the fight against inequality, it is not a solution to rural Ferlo where water is scarce.

\section{References}

[1] World Health Organization (2011) Promotion of Oral Health. Newsletter of the WHO Office in 2003. http://www.who.int/disasters/repo/10239.pdf

[2] World Health Organization (1996) Regional Strategy for Oral Health 1998-2008. WHO, Geneva. http://www.aoi-fr.org/missions/mada/pnsbd final AOI 01 juil10.pdf

[3] Soames, J.V. and Southam, J.C. (2002) Dental Caries: The Disease and Its Clinical Management. Oral Pathology. 3rd Edition, Blackwell Munksgaard, Oxford, 82.

[4] Nörmark, S. (1993) Social Indicators of Dental Caries among Sierra Leonean Schoolchildren. Scandinavian Journal of Dental Research, 101, 121-129. http://dx.doi.org/10.1111/j.1600-0722.1993.tb01650.x

[5] de Silva-Sanigorski, A.M., Waters, E., Calache, H., Smith, M., Gold, L., Gussy, M., Scott, A., Lacy, K. and VirgoMilton, M. (2011) Splash!: A Prospective Birth Cohort Study of the Impact of Environmental, Social and Family-Level Influences on Child Oral Health and Obesity Related Risk Factors and Outcomes. BMC Public Health, 11, 505. http://dx.doi.org/10.1186/1471-2458-11-505

[6] Cisse, D. (1997) Traditional and Modern Treatment in Odontostomatology in Senegal: Historical Sketches. Retrospective and Prospective Research. 3rd Cycle Thesis, Chir. Tooth. Dakar, \# 40.

[7] Diouf, M., Cisse, D., Lo, C.M., Faye, D., Faye, B., Benoist, H.M. and Souare, N. (2009) Evaluation of the Need for Periodontal Treatment in Prisons near Dakar, Senegal. Médecine Tropicale, 69, 587-590.

[8] Ancelle, T. (2003). Statistics Epidemiology. Editions Maloine, Paris, 300.

[9] Diouf, M., Boetsch, G., Tal-Dia, A., Tavitian, P. and Bontil, J.J. (2012) Lifestyles and Oral Health in Fulani Populations of Ferlo in Senegal. Médecine et Santé Tropicales, 22, 187-192.

[10] WHO (2013) Oral Health Survey: Basic Methods. http://www.icd.org/content/publications/WHO-Oral-Health-Surveys-Basic-Methods-5th-Edition-2013.pdf

[11] Olabisi, A.A., Udo, U.A., Ehimen, U.G., Bashiru, B.O., Gbenga, O.O. and Adeniyi, A.O. (2015) Prevalence of Dental Caries and Oral Hygiene Status of a Screened Population in Port Harcourt, Rivers State, Nigeria. Journal of International Society of Preventive \& Community Dentistry, 5, 59-63. http://dx.doi.org/10.4103/2231-0762.151979

[12] Maru, A.M. and Narendran, S. (2012) Epidemiology of Dental Caries among Adults in a Rural Area in India. Journal of Contemporary Dental Practice, 13, 382-388. http://dx.doi.org/10.5005/jp-journals-10024-1155

[13] Mathese, M., Baelum, V., Aarslev, I., et al. (1986) Dental Health of Children and Adults in Guinea-Bissau, West Africa. Community Dent Health, 7, 123-133.

[14] Petersen, P.E. and Mzee, M.O. (1998) Oral Health Profile of Schoolchildren, Mothers and Schoolteachers in Zanzibar. Community Dent Health, 15, 256-262. 
[15] Varenne, B., Petersen, P.E. and Ouattara, S. (2004) Oral Health Status of Children and Adults in Urban and Rural Areas of Burkina Faso, Africa. International Dental Journal, 54, 83-89. http://dx.doi.org/10.1111/j.1875-595X.2004.tb00260.x

[16] Ndanu, T.A., Aryeetey, R., Sackeyfio, J., Otoo, G. and Lartey, A. (2015) Oral Hygiene Practices and Caries Prevalence among 9-15 Years Old Ghanaian School Children. Journal of Nutrition and Health Sciences, 2, 1-8. 